\title{
Investigation of deleterious effects of chromium phytotoxicity and photosynthesis in wheat plant
}

\author{
S. MATHUR ${ }^{*}$, H.M. KALAJI ${ }^{* *+}$, and A. JAJOO*,+ \\ School of Life Science, Devi Ahilya University, Indore 452017, MP, India* \\ Warsaw University of Life Sciences (SGGW), 02-964 Warsaw, Poland**
}

\begin{abstract}
Increasing human and industrial activities lead to heavy metal pollution. Heavy metal chromium $(\mathrm{Cr})$ is considered to be a serious environmental contaminant for the biota. Phytotoxic effects of $\mathrm{Cr}$ were studied in wheat plants. Growth parameters were largely inhibited as a result of disturbances in the plant cell metabolism in response to $\mathrm{Cr}$ toxicity. Chromium toxicity led to decline in a number of active reaction centres of PSII, rate of electron transport, and change in PSII heterogeneity. Chromium did not cause any change in heterogeneity of the reducing side. A significant change in antenna size heterogeneity of PSII occurred in response to Cr toxicity. Chromium seems to have extensive effects on the light harvesting complex of PSII.
\end{abstract}

Additional key words: Chl $a$ fluorescence; growth; photosystem II; PSII heterogeneity; wheat.

\section{Introduction}

Heavy metals (HM) are innately present as trace elements in environment and their presence is marked in soil, water etc. The term ,heavy metals“ refers to any metallic element that has a relatively high density and is toxic or poisonous even at a low concentration. In general, the term applies to the group of metals and metalloids with atomic density greater than $4 \mathrm{~g} \mathrm{~cm}^{-3}$, five times or more greater than water (Hawkes 1997). However, chemical property of $\mathrm{HM}$ is regarded as a more influencing factor in comparison to its density (Gill 2014). Their presence in soils is in the form of free metal ions, soluble metal complexes, organically bound metals, exchangeable metal ions, precipitated or insoluble compounds, such as carbonates and oxides (Shanker et al. 2005). The excessive augmentation of HM in nature is causing hazardous affects on plants, animals, and human. Once these HM cross the threshold and enter the food chain through any of sources, their mushrooming is impossible to end. HM stress triggers different responses in plants, ranging from biochemical responses to crop yield.
Amongst HM, the effects of $\mathrm{Cr}$ on living organisms have received highlighted attention due to strong toxicity and a relatively less known mode of action. Soil and ground water contamination due to excessive use of $\mathrm{Cr}$ by various anthropogenic activities has become a serious problem for plants and animals over the past few decades (Gill et al. 2015, Shanker et al. 2005). Cr is a transition element classified into the group VI-B of the periodic table with a ground-state electronic configuration of $\mathrm{Ar} 3 \mathrm{~d}^{5} 4 \mathrm{~s}^{1}$. The stable forms of $\mathrm{Cr}$ are the trivalent $\mathrm{Cr}$ (III) and the hexavalent $\mathrm{Cr}(\mathrm{VI})$ species, although there are various other valence states which are unstable and short lived in biological systems. $\mathrm{Cr}(\mathrm{VI})$ is considered the most toxic form of $\mathrm{Cr}$, which usually occurs associated with oxygen as chromate $\left(\mathrm{CrO}_{4}{ }^{2-}\right)$ or dichromate $\left(\mathrm{Cr}_{2} \mathrm{O}_{7}{ }^{2-}\right)$ oxyanions. These compounds are widely engaged in leather processing and finishing, in the production of refractory steel, drilling muds, electroplating cleaning agents, catalytic manufacture, and in the production of chromic acid and special chemicals. Hexavalent $\mathrm{Cr}$

Received 18 July 2015, accepted 6 January 2016, published as online-first 18 January 2016.

${ }^{+}$Corresponding authors; e-mail: anjanajajoo@hotmail.com; hazem@,kalaji.pl

Abbreviations: ABS - absorption; Chl $a$ - chlorophyll $a$; $\overline{\mathrm{CS}}$ - cross section; DCMU - 3-(3,4-dichlorophenyl)-1,1-dimethyl urea; $\mathrm{Di}_{0}$ - dissipation; $\mathrm{DM}$ - dry mass; $\mathrm{ET}_{0}$ - electron transport; $\mathrm{F}_{0}$ - initial fluorescence; $\mathrm{F}_{\mathrm{M}}$ - maximum fluorescence; $\mathrm{FM}$ - fresh mass; $\mathrm{F}_{\mathrm{V}}$ - variable fluorescence; HM - heavy metal; OJ, JI, IP - phases of Chl $a$ fluorescence induction curve; PEA - plant efficiency analyser; $\mathrm{PQ}$ - plastoquinone; $\mathrm{RC}$ - reaction centre; $\mathrm{TR}_{0}$ - trapping.

Acknowledgements: S. Mathur thanks to University Grant Commission, (UGC), India for Post Doctoral Fellowship for Women-SAII (PDFWM-2014-15-GEMAD-23945). A. Jajoo thanks Department of Science and Technology, New Delhi, India (DST) for the project (DST/RUS/RFBR/P-173). We are also thankful to Prof. R.J. Strasser and R. Maldonado-Rodriguez for gifting Biolyzer HP 3 software. “C The Author(s)." This article is published with open access at link.springer.com 
compounds are mainly used in various industries for metal plating, cooling tower water treatment, hide tanning, and wood preservation. The toxic properties of $\mathrm{Cr}(\mathrm{VI})$ originate from the action of this form itself as an oxidizing agent, as well as from the formation of free radicals during the reduction of $\mathrm{Cr}(\mathrm{VI})$ to $\mathrm{Cr}(\mathrm{III})$ occurring inside the cell.

Chromium compounds are highly toxic to plants and are detrimental to their growth and development. Presence of $\mathrm{Cr}$ in the external environment influences growth and development of plants. It has been found that $\mathrm{Cr}$ caused stunting plant growth, chlorosis in new leaves, wilting of tops, impaired photosynthesis, damage of roots, and finally plant death (Sharma et al. 2003, Scoccianti et al. 2006). The overall adverse effect of $\mathrm{Cr}$ on growth and development of plants could be serious impairment in uptake of mineral nutrients and water leading to deficiency in shoots. In addition, the normal mechanism of selective inorganic nutrient uptake might be destroyed by oxidative damage, thus permitting larger quantities of $\mathrm{Cr}(\mathrm{VI})$ to enter roots passively and further translocation of $\mathrm{Cr}(\mathrm{VI})$ to shoots causing oxidative damage to the photosynthetic and mitochondrial apparatus eventually reflected in poor growth. Furthermore, plants growing in Cr-stressed environments also stimulate the formation of reactive oxygen species (ROS), which can harm the production of biomolecules, such as lipids, proteins, and nucleic acids, thereby, interrupting both mitochondrial respiration and carbohydrate metabolism (Gill and Tuteja 2010, Gill et al. 2015). Cr stress is one of the important factors that affect photosynthesis in terms of $\mathrm{CO}_{2}$ fixation, electron transport, photophosphorylation, and enzyme activities. However, it is not well understood to what extent $\mathrm{Cr}$-induced inhibition of photosynthesis occurs due to disorganization of chloroplasts ultrastructure (Vázques et al. 1987), inhibition of electron transport or the influence of $\mathrm{Cr}$ on enzymes of the Calvin cycle. It was investigated that $\mathrm{Cr}$ -

\section{Materials and methods}

Plant material: Wheat (Triticum aestivum; Purna HI 1544) cultivar was used as plant material. Uniform seeds were selected for sowing.

Plant cultivation/growth: Wheat seeds were sown in soil and allowed to germinate in $15 \mathrm{~cm}$ (length) plastic pots containing $700 \mathrm{~g}$ of soil. Ten seeds were sown in each pot. After seedling emergence, ten seedlings were reduced/thinned to six seedlings per pot. The plantlets were allowed to grow under control conditions in a culture room. The plants were grown under $8 / 16 \mathrm{~h}$ of light/dark regime. The plants were allowed to grow till 3-4 mature leaf stage. Cultivation was done under PPFD of $300 \mu \mathrm{M}$ $\mathrm{m}^{-2} \mathrm{~s}^{-1}$ at $22-25^{\circ} \mathrm{C} \pm 2^{\circ} \mathrm{C}$. The plants were daily replenished with normal tap water (control) and with different concentrations of $\mathrm{Cr}$ until $40 \mathrm{~d}$. All the measurements were performed with different concentrations of $\mathrm{Cr}$ on 25,35 , and $40 \mathrm{~d}$ (DAT). Since maximum changes were toxicity caused ultrastructural changes apparent as poorly developed lamellar system with widely spaced thylakoids and fewer grana (Ali et al. 2013a). This aberration in thylakoid membrane might have some negative impact on photosynthesis and excitation energy transfer imbalance may also occur (Ali et al. 2013a). Nevertheless, it is not clear at what concentration $\mathrm{Cr}$ induces the ultrastructural changes in chloroplasts and causes the inhibition of photosynthesis (Ali et al. 2013a,b; Gill et al. 2015).

In this study, we estimated photosynthetic efficiency of Cr-stressed plants by the technique of fast chlorophyll (Chl) $a$ fluorescence induction measurement which were analysed to obtain comprehensive information on effects of $\mathrm{Cr}$ on the primary events and electron transport of photosynthesis. Fast Chl $a$ fluorescence induction is an informative tool for studying the effects of various environmental stresses on the process of photosynthesis, particularly on the function of PSII and its reactions (Lazár 2006, Tomar and Jajoo 2013, Kalaji et al. 2014, Brestič et al. 2015). The first second of the fast induction curve is characterized by three apparent kinetic steps denoted OJ, JI, and IP. These phases of fluorescence induction have been correlated with peak accumulation of different reduced species on the acceptor side of PSII. Due to potential destructive capability of HM on biological membranes, photosynthetic pigments, and proteins at cellular level, effects of $\mathrm{Cr}(\mathrm{VI})$ could be assessed by means of $\mathrm{Chl}$ fluorescence characterizing alterations in the functioning of PSII. Aim of this study was to understand more precisely the role and target of chromate on the photosynthetic apparatus. This study combined growth parameters along with changes occurring at PSII level, especially PSII heterogeneity, which has received strong attention recently because of its role in adaptation to stress conditions.

observed after 25 DAT and leaves started to become yellow after 30 DAT, the data obtained after 25 DAT were discussed in this paper.

Chromium treatment: $\mathrm{Cr}$ was used in dichromate form to detect toxicity in plants. It was prepared from potassium dichromate (Fisher Scientific Qualigens, Thermo Fisher Scientific; India). The stock solution $\left(20 \mathrm{mM} \mathrm{K}_{2} \mathrm{Cr}_{2} \mathrm{O}_{7}\right)$ was prepared. For the treatment, we used $100 \mu \mathrm{M}, 200 \mu \mathrm{M}$, and $300 \mu \mathrm{M}$ concentrations of $\mathrm{Cr}$. The plants without any $\mathrm{Cr}$ were considered as control.

Growth and germination: To measure a rate of germination in plantlets, 50 seeds were used per one Petri plate. The germination rate was expressed as the percentage of plantlets germinated from the total number of seeds $(100 \%)$. Fresh and dry mass (FM and DM) of shoots was determined in five replicates (three plants of each set 
randomly selected) of the control and treated plants. For $\mathrm{DM}$ estimation, the individual plants were oven-dried at $80^{\circ} \mathrm{C}$ for $4 \mathrm{~h}$

Fast Chl $\boldsymbol{a}$ fluorescence induction kinetics was measured at room temperature using a plant efficiency analyzer (PEA, Hansatech, England). The light was provided by an LED array of $650 \mathrm{~nm}$ focused onto the sample to provide homogeneous irradiance over the exposed area $(\mathrm{d}=4 \mathrm{~mm})$. Light intensity reaching the leaf was 3,000 $\mu \mathrm{mol}$ (photon) $\mathrm{m}^{-1} \mathrm{~s}^{-1}$ which was sufficient to generate maximal fluorescence $\left(\mathrm{F}_{\mathrm{M}}\right)$ for all the treatments. All samples were darkadapted for $30 \mathrm{~min}$ prior to the measurements. The JIP-test is named after the basic steps in the fluorescence transient when plotted on a logarithmic time scale. The shape of the O-J-I-P fluorescence rise has been related to a major change in the photosynthetic electron transport (Joly and Carpentier 2009, Papageorgiou and Govindjee 2011). Control leaves exhibited a polyphasic rise called O-J-I-P $\mathrm{Chl} a$ fluorescence transient. The fluorescence intensities at $50 \mu \mathrm{s}$ (O-step), $2 \mathrm{~ms}$ (J-step), and $30 \mathrm{~ms}$ (I-step) and $500 \mathrm{~ms}$ (P-step) were denoted as as $\mathrm{F}_{0}, \mathrm{~F}_{\mathrm{J}}, \mathrm{F}_{\mathrm{I}}$, and $\mathrm{F}_{\mathrm{M}}$ respectively [Strasser et al. 2004 (Fig. 1), Chen and Cheng 2009], as described in Appendix. Measurements were done $5 \mathrm{~cm}$ away from tip and base of the plants, i.e., in the middle part of the fully developed leaves. Fifteen to twenty measurements were done for each replicate.

Energy pipeline leaf model and flux ratios: Biolyzer $H P-3$ software was used to deduce energy pipeline leaf model [i.e., activities expressed per excited cross section (CS) and flux ratios]. Yield or flux ratios were calculated

\section{Results and discussion}

Growth parameters: HM, especially $\mathrm{Cr}$, phytotoxicity has negative effects on the crop yield. Plant morphology in terms of leaf length, number of leaves, and leaf area per plant, FM, DM, and percentage of the plants germinated per pot were studied in response to various $\mathrm{Cr}$ concentrations (Table 1). Cr interferred with various metabolic processes and was toxic to the plants; it was exhibited by stunted growth, reduced root growth, phytomass chlorosis, photosynthetic impairing, stunting, and finally by plant death (Table 1). In comparison with control (100\% plantlet germination), the rate of germination remained only $30 \%$ at higher $\mathrm{Cr}$ concentrations (Table 1). The reduced germination of plantlets could represent a depressive effect of $\mathrm{Cr}$ on the activity of amylases (Shanker et al. 2005).

It is established that the leaf number, leaf growth area, etc. determine the crop yield. Table 1 clearly indicates that the leaf numbers decreased drastically after the treatment with 200 and $300 \mu \mathrm{M}$ Cr. Deleterious effects of $\mathrm{Cr}$ was maximal on shoot and leaf growth and development. The reduced plant height at higher $\mathrm{Cr}$ concentrations may be according to Mathur et al. (2013), Mathur and Jajoo (2015), and Strasser et al. (2004) and are described in Appendix.

\section{PSII heterogeneity}

Antenna heterogeneity: For determination of antenna heterogeneity, 3-(3',4'-dichlorophenyl)-1,1-dimethylurea (DCMU) poisoning method was used (Hsu et al. 1989). The method was previously described in Tóth et al. (2005) and Mathur et al. (2011). Alpha $(\alpha)$, beta $(\beta)$, and gamma $(\gamma)$ centers were calculated from the complementary area of the growth curve. The antenna heterogeneity was also calculated on the basis of connectivity by the method described in Tóth et al. (2005) and Mathur et al. (2011).

Heterogeneity of the reducing side: Double hit (pulse) method was followed for the calculation of $\mathrm{Q}_{\mathrm{B}}$ reducing and $\mathrm{Q}_{\mathrm{B}}$-nonreducing centres (Strasser and TsimilliMichael 1998). In this method, two fluorescence transients were induced by two subsequent pulses each of 1-s duration. $\mathrm{Q}_{\mathrm{B}}$-reducing and $\mathrm{Q}_{\mathrm{B}}$-nonreducing centres were calculated as described in Mathur et al. (2011).

Statistical analysis: Data was analyzed by using Graph pad Prism 5.01 software (La Jolla, CA, USA). Results were analyzed using one way analysis of variance (ANOVA) followed by Newman-Keul's multiple comparison test. Significance was determined at $p<0.001$ $\left({ }^{*} p<0.05, * * p<0.01\right.$, and $\left.* * * p<0.001\right)$ and the results are expressed as mean values and standard deviation (SD) and all assays were carried out in replicates (six sets of each analysis).

due to reduced root growth, as reported earlier and results in lesser nutrients and water uptake in plants (Shanker et al. 2005). Wilting, yellowing of the whole plant, and necrosis followed by early senescence was the main physiological change observed in our study in wheat plants in response to enhanced $\mathrm{Cr}$ concentration.

Primary condition for the higher crop yield and production in plants is estimated in terms of enhancement in biomass production. Biomass production in terms of FM and DM showed also a negative trend in response to the increased $\mathrm{Cr}$ concentrations indicating that $\mathrm{Cr}$ had phytotoxic effects at the higher concentrations. DM was severely affected by the increasing $\mathrm{Cr}$ concentrations (Table 1). The overall adverse effect of $\mathrm{Cr}$ on growth and development of wheat could be due to impairment of uptake of mineral nutrients leading to retarded plant growth. This reduction in plant growth in response to $\mathrm{Cr}$ during early stages affects the crop yield of wheat in later stages. 
Table 1. Effect of various $\mathrm{Cr}$ concentrations on different growth parameters in wheat plants. Each experiment is a repetition of six replicates with five plants each. Values are given as mean \pm SD. Significant differences were calculated according to Newman-Keuls' multiple comparison test at $p<0.001$.

\begin{tabular}{llccc}
\hline Cr treatment $[\mu \mathrm{M}]$ & Leaf length $[\mathrm{cm}]$ & Fresh mass [\%] & Dry mass [\%] & Plant germinated per pot [\%] \\
\hline Control & $27.5 \pm 2$ & $100 \pm 1$ & $100 \pm 1$ & $100 \pm 1$ \\
100 & $18.3 \pm 2^{* * *}$ & $57 \pm 1^{* * *}$ & $50 \pm 1^{* * *}$ & $80 \pm 2^{* * *}$ \\
200 & $12.5 \pm 2^{* * *}$ & $80 \pm 1^{* * *}$ & $55 \pm 2^{* * *}$ & $50 \pm 2^{* * *}$ \\
300 & $7.5 \pm 3^{* * *}$ & $87 \pm 2^{* * *}$ & $75 \pm 2^{* * *}$ & $30 \pm 1^{* * *}$ \\
\hline
\end{tabular}

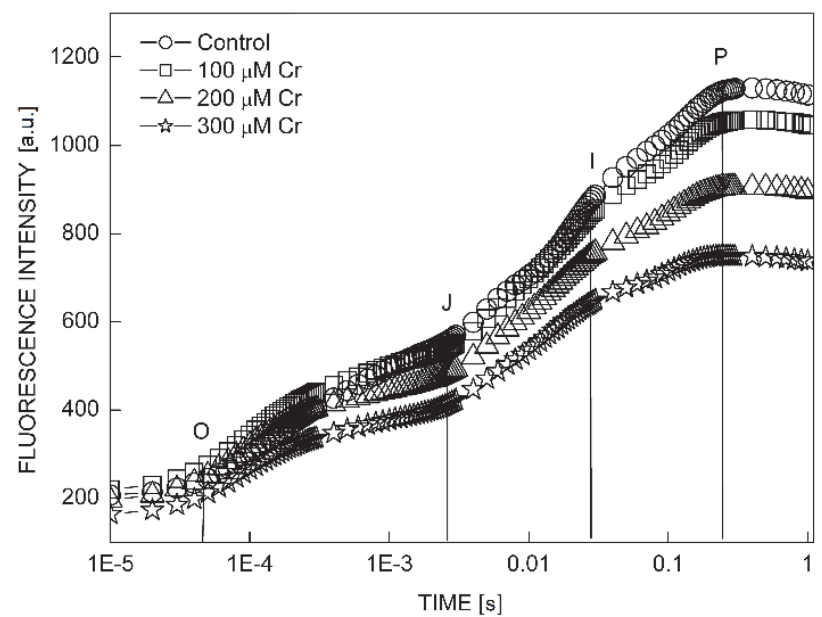

Fig. 1. Change in Chl $a$ fluorescence induction curves (OJIP) plotted on logarithmic scale in control and various $\mathrm{Cr}$ concentration in wheat plants.

Effect of $\mathrm{Cr}$ on $\mathrm{Chl} \boldsymbol{a}$ fluorescence parameters: Inhibition in the plant growth parameters was a result of disturbances in the plant cell metabolism in response to $\mathrm{Cr}$ toxicity. $\mathrm{Cr}$ interferes with photosynthetic processes and thus Chl $a$ fluorescence measurement can reveal the inhibition caused by $\mathrm{Cr}$ at different levels in the photosynthetic apparatus. The control plants exhibited a polyphasic rise called $\mathrm{O}-\mathrm{J}-\mathrm{I}-\mathrm{P}$ transient (Fig. 1). The increase in the $\mathrm{Cr}$ concentration caused significant inhibition of $\mathrm{F}_{\mathrm{M}}$ while no change was observed in $\mathrm{F}_{0}$ (Fig. 1). The J, I, and $\mathrm{P}$ phase was inhibited with the increasing $\mathrm{Cr}$ concentration which might occur due to two reasons: first, by inhibition of electron transport at the donor side of PSII which results in the accumulation of $\mathrm{P} 60^{+}$; second, due to a decrease in the pool size of $\mathrm{QA}^{-}$(Govindjee 1995, Neubauer and Schreiber 1987) which was also evident by a decrease in area (Table 2). Changes in various fluorescence parameters were observed in response to the increasing $\mathrm{Cr}$ concentration (Table 2). The ratio of $\mathrm{F}_{\mathrm{V}} / \mathrm{F}_{\mathrm{M}}$ represents the conversion and capture efficiency of primary light energy and is an excellent measure for the evaluation of quantum yield of primary photochemistry of PSII (Butler and Kitajima 1975, Strasser 2004, Subrahmanyam 2008, Mathur and Jajoo 2015) (Appendix). A gradual decline in $\mathrm{F}_{\mathrm{V}} / \mathrm{F}_{\mathrm{M}}$ ratio (Table 2) suggested that $\mathrm{Cr}$ decreased the quantum efficiency of PSII photochemistry either by causing a decrease in the rate of primary charge separation or by disconnection of some minor antenna from PSII. Area represents the area over the fluorescence induction curve between $F_{0}$ and $F_{M}$ and is proportional to the pool size of the electron acceptor $\mathrm{Q}_{\mathrm{A}}$ on the reducing side of PSII and also $\mathrm{Q}_{\mathrm{B}}, \mathrm{PQ}$, and PSI acceptors (Strasser et al. 2004). Linear drop in the area with the enhanced $\mathrm{Cr}$ concentration indicated that the electron transfer from the reaction center to quinone pool was blocked (Table 2, Fig. 1). Nearly $61 \%$ decrease was obtained in the area at $300 \mu \mathrm{M} \mathrm{Cr}$. The density of active PSII reaction centers per $\mathrm{Chl}$ and the antenna size of $\mathrm{Chl}$ molecules are represented by the ratio of RC/ABS (Christen et al. 2007, Mathur and Jajoo 2015). The $\mathrm{Cr}$ treatment decreased the number of active reaction centres per $\mathrm{Chl}$ (Table 2). As compared with the control, the ratio of $\mathrm{F}_{\mathrm{V}} / \mathrm{F}_{0}$ decreased by 20,27 , and $30 \%$ in 100,200 , and $300 \mu \mathrm{M} \mathrm{Cr}$, respectively. This shows that maximum damage to water splitting complex of PSII occurred at $300 \mu \mathrm{M}$ (Kalaji et al. 2012). This decrease also indicated an impairment of PSII photochemistry (Chen and Cheng 2009, Essemine et al. 2012, Kalaji et al. 2012).

Table 2. Effect of various $\mathrm{Cr}$ concentrations on different chlorophyll (Chl) $a$ transients in wheat plants. Each experiment is a repetition of six replicates with five plants each. Values are given as mean \pm SD. Significant differences were calculated according to Newman-

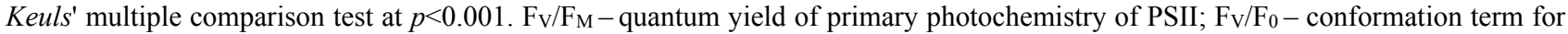
primary photochemistry; $\mathrm{PI}(\mathrm{ABS})$ - performance index on the basis of absorbance; RC/ABS - density of active PSII reaction centers per $\mathrm{Chl}$ and the antenna size of Chl molecules.

\begin{tabular}{llllll}
\hline Cr treatment $[\mu \mathrm{M}]$ & $\mathrm{Fv} / \mathrm{FM}_{\mathrm{M}}$ & Area & $\mathrm{RC} / \mathrm{ABS}$ & $\mathrm{FV} / \mathrm{F}_{0}$ & $\mathrm{PI}(\mathrm{ABS})$ \\
\hline Control & $0.823 \pm 0.03$ & $29620 \pm 74$ & $0.939 \pm 0.01$ & $4.655 \pm 1$ & $26 \pm 1$ \\
100 & $0.788 \pm 0.02^{* *}$ & $24778 \pm 87^{* * *}$ & $0.764 \pm 0.02^{* * *}$ & $3.707 \pm 1^{* *}$ & $17 \pm 1^{* * *}$ \\
200 & $0.773 \pm 0.01^{* *}$ & $17626 \pm 75^{* * *}$ & $0.686 \pm 0.04^{* * *}$ & $3.398 \pm 1^{* *}$ & $13 \pm 2^{* * *}$ \\
300 & $0.768 \pm 0.02^{* *}$ & $11548 \pm 58^{* * *}$ & $0.678 \pm 0.05^{* * *}$ & $3.31 \pm 1^{* *}$ & $12 \pm 1^{* * *}$ \\
\hline
\end{tabular}


$\mathrm{PI}_{(\mathrm{ABS})}$ represent the performance index on absorbance basis. $\mathrm{PI}_{(\mathrm{ABS})}$ is a very sensitive index for stress and is used widely to compare the whole primary photochemical reactions (Chen and Cheng 2009) (Appendix) because it combines three main structural and functional characteristics of PSII, (1) a component referring to the density of active PSII reaction centres per Chl (RC/ABS), (2) a component that describes the performance of the light reactions as $\Phi_{\mathrm{PO}} /\left(1-\Phi_{\mathrm{PO}}\right)$, and (3) a component that describes performance of the dark redox reactions defined as $\psi_{\mathrm{O}} /\left(1-\psi_{\mathrm{O}}\right)$. The performance index $\mathrm{PI}_{(\mathrm{ABS})}$ is derived according to the principles of the Nernst equation for redox reactions (Christen et al. 2007). $\mathrm{PI}_{(\mathrm{ABS})}$ decreased around 35 , 50, and $54 \%$ with 100,200 , and $300 \mu \mathrm{M}$ of $\mathrm{Cr}$ (Table 2), respectively. This shows that the primary photochemical reactions were affected with the higher $\mathrm{Cr}$ content.

An alteration of PSII energy fluxes in response to $\mathrm{Cr}$ phytotoxicity was also visualized by energy pipeline models of photosynthetic apparatus. Fig. 2 depicts energy pipeline leaf model that refers to the leaf cross-section (CS). This model deals with the phenomenological fluxes (Appendix). Leaf models were deduced using Biolyzer HP-3 software. This is a dynamic model, where the energy fluxes in the control and $\mathrm{Cr}$-treated plants were expressed by the width of the corresponding arrows. The model also shows the changes in the active and inactive PSII reaction centres per cross-section ( $\mathrm{RC} / \mathrm{CS})$, as well as the flux of dissipated excitation energy at time zero $\left(\mathrm{DI}_{0}\right)$. Various parameters, such as the efficiency of light absorption, trapping, and electron transport and dissipation per cross section of PSII, are indicated by $\mathrm{ABS} / \mathrm{CS}_{\mathrm{m}}, \mathrm{TR} / \mathrm{CS}_{\mathrm{m}}$, $\mathrm{ET} / \mathrm{CS}_{\mathrm{m}}$ and $\mathrm{DI}_{0} / \mathrm{CS}_{\mathrm{m}}$, respectively (where $\mathrm{CS}_{\mathrm{m}}$ corresponds to $\mathrm{F}_{\mathrm{m}}$ ). It is evident that the increasing $\mathrm{Cr}$ concentrations declined $\mathrm{ABS} / \mathrm{CS}_{\mathrm{m}}, \mathrm{ET}_{0} / \mathrm{CS}_{\mathrm{m}}, \mathrm{TR}_{0} / \mathrm{CS}_{\mathrm{m}}$ ratios (Fig. 2). The decline in $\mathrm{ABS} / \mathrm{CS}_{\mathrm{m}}$ indicated a decrease of the energy absorbed per excited cross-section (TsimilliMicheal and Strasser 2008). Electron transport decreased after the $\mathrm{Cr}$ treatment as compared with the control plants indicating lower energy absorption by antenna pigments $\left(\mathrm{ABS} / \mathrm{CS}_{\mathrm{m}}\right)$ and inactivation of reaction centre complexes. $\mathrm{Cr}$ acted on active reaction centers producing dissipative sinks for excitation energy (Appenroth et al. 2001). The ratio of $\mathrm{TR}_{0} / \mathrm{CS}_{\mathrm{m}}$ gradually decreased with the increasing $\mathrm{Cr}$ concentration indicating that trapping of reaction centers was affected significantly. The decrease in the density of active reaction centers and the increase in the density of closed reaction centers (also known as inactive centers) was observed as a negative effect of $\mathrm{Cr}$. The change in trapping could be a result of modified ABS (Fig. 2).

Further analysis of the $\mathrm{Cr}$ treatment was done on the basis of parameters, such as $\delta_{\mathrm{R} 0}, \varphi_{\mathrm{R} 0}, \mathrm{SF}_{(\mathrm{ABS})}, \mathrm{DF}, \varphi_{\mathrm{E} 0}$ (Appendix), which are considered as electron transport parameters since these parameters furnish actual status of the electron transport rate in PSII. These parameters decreased with the increasing $\mathrm{Cr}$ concentrations. $\delta_{\mathrm{RO}}$
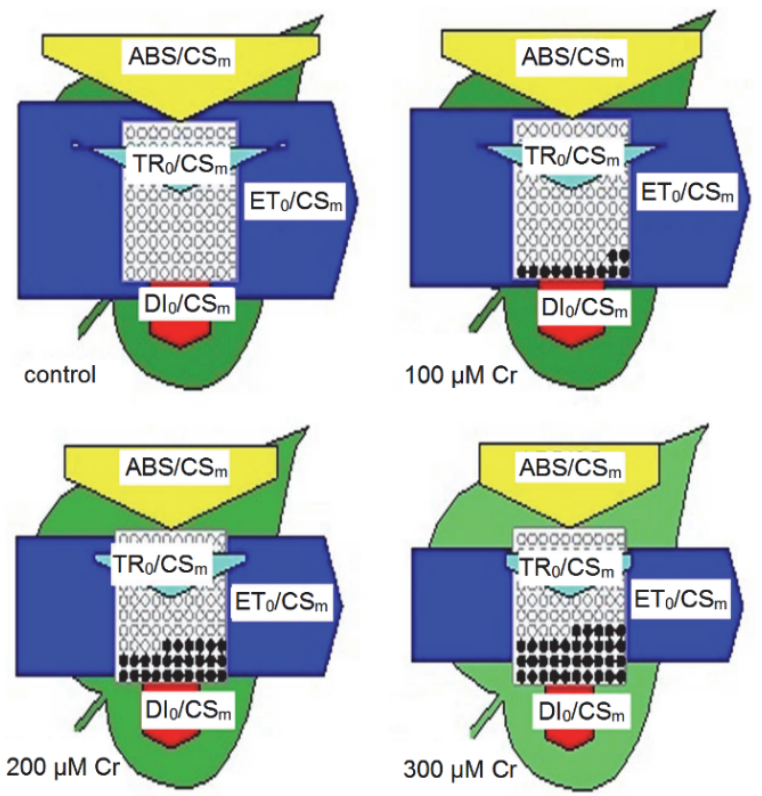

Fig. 2. Energy pipeline leaf model showing changes in phenomenological fluxes or apparent activities per cross section (CS) for control and different $\mathrm{Cr}$ concentrations. The fluxes used represent light absorbance (ABS), excitation energy trapping (TR), electron transport (ET), and energy dissipation $\left(\mathrm{DI}_{0}\right)$ beyond $\mathrm{Q}_{\mathrm{A}}^{-}$. Open circles (active) and closed circles (inactive) PSII reaction centres per cross-section (RC/CS). For description of parameters, see text and Appendix.

$\left(\mathrm{RE}_{0} / \mathrm{ET}_{0}\right)$ indicates efficiency with which an electron can move from the reduced intersystem electron acceptors to the PSI end electron acceptors (Chen and Cheng 2009). $\delta_{\mathrm{RO}}$ is dependent on electrons transferred from $\mathrm{PQH}_{2}$ to PSI. $\delta_{\text {RO }}$ decreased slightly after enhanced $\mathrm{Cr}$ exposure suggesting that $\mathrm{Cr}$ reduced the efficiency of electrons to reach PSI end electron acceptors. $\varphi_{\text {RO }}$ represents quantum yield of the electron transport from $\mathrm{Q}_{\mathrm{A}}-$ to the PSI end electron acceptors (Chen and Cheng 2009). The value of $\varphi_{\mathrm{R} 0}$ did not decrease significantly in both 200 and $300 \mu \mathrm{M}$ $\mathrm{Cr}$ (Fig. 3) indicating the quantum yield of electron transport from $\mathrm{Q}_{\mathrm{A}}-$ to PSI end electron acceptor decreased. It is also supported by the fact that $\mathrm{Q}_{\mathrm{A}}-$ was unable to reduce back due to $\mathrm{Cr}$ stress. $\mathrm{SFI}_{(\mathrm{ABS})}$ is the product of three independent parameters, RC/ABS, $\varphi_{\mathrm{PO}}, \Psi_{0}$. These three have been used as an expression, which represents an index combining functional and structural criteria of PSII, denoted as the structure function index for photosynthetic system (Srivastava et al. 1999, Appenroth et al. 2001). It is represented as:

$$
\mathrm{SFI}_{(\mathrm{ABS})}=\left(\mathrm{Chl}_{\mathrm{RC}} / \mathrm{Chl}_{\text {tot }}\right) \times \varphi_{\mathrm{PO}} \times \Psi_{\mathrm{O}}
$$

A decrease in $\mathrm{SFI}_{(\mathrm{ABS})}$ was observed with the increasing $\mathrm{Cr}$ concentration. This indicated that $\mathrm{Cr}$ caused toxic effects and plants were unable to cope with stress conditions. The driving force (DF) (Srivastava et al. 1999), which quantifies the potential of plant photosynthesis, decreased with the enhanced $\mathrm{Cr}$ concentration (data not 
shown) and indicated that plants were under stress. $\varphi$ EO has direct impact on the electron transport and represents the quantum yield for the electron transport at $\mathrm{t}=0 . \mathrm{Cr}$ decreased the linear electron transport rate (also expressed as probability that an absorbed photon moves an electron further than to $\mathrm{Q}_{\mathrm{A}}{ }^{-}$) which was depicted by a decreased $\varphi_{\text {EO }}$ value (Fig. 3). Retardation in electron transport processes due to $\mathrm{Cr}$ and a diversion of electrons from the electron-donating side of PSI to $\mathrm{Cr}$ is a probable justification for $\mathrm{Cr}$ induced decline in the photosynthetic rate. It is likely that electrons produced by the photochemical process were not essentially used for carbon fixation as supported by the decreased photosynthetic rate in the Cr-treated wheat plants. Due to the known oxidative potential of $\mathrm{Cr}$, it is possible that alternative sinks for electrons possibly were enhanced by reduction of molecular oxygen (part of Mehler reaction) which to some extent explains the oxidative stress caused by $\mathrm{Cr}$ (Shanker et al. 2005).

Effect of Cr toxicity on PSII heterogeneity: Different from other pigment protein complexes participating in photosynthetic light reaction, PSII shows diversity in its nature in functional and structural aspects known as PSII heterogeneity. Investigations of PSII heterogeneity in early stages of plant's life cycle is a promising measure to detect stress conditions and tolerance in plants. PSII has been found to undergo changes in its structural and functional heterogeneity in response to different abiotic stresses, such as salinity (Tomar et al. 2012), organic pollutants (Tomar and Jajoo 2015), and high temperature stress (Mathur et al. 2011).

By using kinetic analysis of fluorescence induction curve with DCMU-poisoned chloroplasts (Tóth et al. 2005, Mathur et al. 2011), PSII has been distinguished into three components on the basis of antenna size, i.e., PSII ${ }_{\alpha}$, $\mathrm{PSII}_{\beta}$, and $\mathrm{PSII}_{\gamma}$. This method can provide direct information about the lifetime and the relative proportions of $\operatorname{PSII}(\alpha), \operatorname{PSII}(\beta)$, and $\operatorname{PSII}(\gamma)$ under the increasing $\mathrm{Cr}$ concentrations in wheat plants. In case of antenna heterogeneity, increased $\mathrm{Cr}$ caused changes in the relative amount of $\alpha, \beta$, and $\gamma$ centers (Table 3 ). The proportion (in terms of percentage) of $\alpha, \beta$, and $\gamma$ centers was found to be 64:30:6 in control, 61:33:6 at $100 \mu \mathrm{M}, 57: 37: 6$ at $200 \mu \mathrm{M}$,

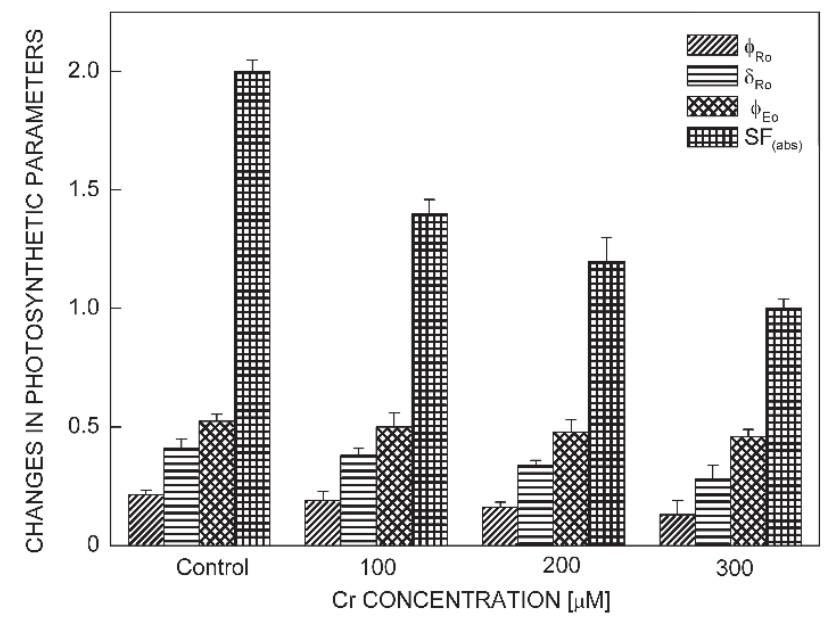

Fig. 3. Changes in various ratios of dark-adapted wheat plants derived from OJIP curves in response to enhanced $\mathrm{Cr}$ concentrations. All the values are relative to the control. For description of the parameters see text and Appendix.

and 50:40:10 at $300 \mu \mathrm{M}$, respectively. At 100 and $200 \mu \mathrm{M}$ $\mathrm{Cr}$ concentration, the active $\alpha$ centers were converted into inactive $\beta$ centers, while at $300 \mu \mathrm{M}$, the active $\alpha$ centers were converted into both $\beta$ and $\gamma$ centers. The maximum active $\alpha$ centers were converted to $\beta$ centers. Alteration in the $\alpha, \beta$, and $\gamma$ center is associated with downregulation of photochemical activity, damage of photosynthetic apparatus, and changes in the antenna organization. Changes in antenna organization following the $\mathrm{Cr}$ treatment involved the dissociation of $\mathrm{PSII}_{\alpha}$ into free LHCII and PSII $\beta$ and the latter migrated from the grana to the nonappressed thylakoid membranes. The antenna heterogeneity was also calculated on the basis of connectivity (data not shown). According to the concept of connectivity (also called grouping), closed PSII reaction centers (RC) may transfer their excitation energy to the open neighbouring PSII units that results in sigmoidal fluorescence rise instead of exponential rise (Strasser et al. 2004, Tóth et al. 2005). Loosing connectivity (ungrouping) between two PSII indicated that the PSII units of treated plants lost connection and became unstable under the increased $\mathrm{Cr}$ concentrations. Complete loss in connectivity was observed at the higher Cr concentrations.

Table 3. Changes in PSII heterogeneity in terms of antenna size heterogeneity (showing percentage of $\alpha, \beta$ and $\gamma$ centers) and amount of Qв-reducing and nonreducing centers in response to different $\mathrm{Cr}$ concentrations. Each experiment is a repetition of six replicates with five plants each. Values are given as mean \pm SD. Significant differences were calculated according to Newman-Keuls' multiple comparison test on $p<0.001$.

\begin{tabular}{|c|c|c|c|c|c|}
\hline \multicolumn{2}{|c|}{ Cr treatment $[\mu \mathrm{M}] \alpha$} & \multirow{2}{*}{$\begin{array}{l}\beta \\
30 \pm 1\end{array}$} & \multirow{2}{*}{$\begin{array}{l}\gamma \\
6 \pm 1\end{array}$} & \multirow{2}{*}{$\begin{array}{l}\text { Qв reducing } \\
\text { centers }[\%]\end{array}$} & \multirow{2}{*}{$\begin{array}{l}\text { Qв nonreducing } \\
\text { centers }[\%]\end{array}$} \\
\hline Control & $64 \pm 1$ & & & & \\
\hline 100 & $61 \pm 2^{* * *}$ & $33 \pm 1^{* * *}$ & $6 \pm 1$ & $80 \pm 1^{* * *}$ & $20 \pm 2$ \\
\hline 200 & $57 \pm 2^{* * *}$ & $37 \pm 2^{* * *}$ & $6 \pm 2$ & $80 \pm 2^{* *}$ & $20 \pm 1$ \\
\hline 300 & $50 \pm 1^{* * *}$ & $40 \pm 2^{* *}$ & $10 \pm 1^{* * *}$ & $77 \pm 1^{* * *}$ & $23 \pm 2^{* *}$ \\
\hline
\end{tabular}


This indicated that all the PSII units were dissociated from each other due to the $\mathrm{Cr}$ treatment. A number of PSII centers, though photochemically competent, are unable to transfer electrons from electron acceptor $\mathrm{Q}_{\mathrm{A}}-$ to secondary electron acceptor $\mathrm{Q}_{\mathrm{B}}$. These centers are termed as $\mathrm{Q}_{\mathrm{B}}$ nonreducing centers. Reducing side heterogeneity was estimated by measuring relative amounts of $\mathrm{Q}_{\mathrm{B}}$-reducing and $\mathrm{Q}_{\mathrm{B}}$-nonreducing centers as described in Materials and methods. The population of $\mathrm{Q}_{\mathrm{B}}$-nonreducing centers was quantified. In this study, no significant change was observed in the number of $\mathrm{Q}_{\mathrm{B}}$-nonreducing centers (Table 3 ) in response to $\mathrm{Cr}$ stress.
Conclusion: We concluded that $\mathrm{Cr}$ is toxic at different stages of plant growth and development in wheat. It mainly interfered with the photosynthetic machinery. Chromium toxicity led to the decline in the number of active reaction centres of PSII, rate of electron transport, and change in PSII heterogeneity. Chromium did not cause any change in PSII heterogeneity of the reducing side while a significant change in the antenna size heterogeneity of PSII occurred in response to $\mathrm{Cr}$ toxicity. Chromium seemed to have extensive effects on the light harvesting complex of PSII. We conclude that Chl $a$ fluorescence and PSII heterogeneity can be used as a tool for studying photochemical pathways of photosynthesis.

Open Access This article is distributed under the terms of the Creative Commons Attribution License which permits any use, distribution, and reproduction in any medium, provided the original author(s) and the source are credited.

\section{References}

Ali B., Wang B., Ali S. et al.: 5-Aminolevulinic acid ameliorates the growth, photosynthetic gas exchange capacity, and ultrastructural changes under cadmium stress in Brassica napus L. - J. Plant Growth Regul. 32: 604-614, $2013 \mathrm{a}$.

Ali S., Farooq M.H., Hussain S. et al.: Alleviation of chromium toxicity by hydrogen sulfide in barley. - Environ. Toxicol. Chem. 32: 2234-2239, 2013b.

Appenroth K.J., Stöckel J., Srivastava A. et al.: Multiple effects of chromate on the photosynthetic apparatus of Spirodela polyrhiza as probed by OJIP chlorophyll a fluorescence measurements. - Environ. Pollut. 115: 49-64, 2001.

Brestič M., Živčák M., Kunderlíková K. et al.: Low PSI content limits the photoprotection of PSI and PSII in early growth stages of chlorophyll b-deficient wheat mutant lines. Photosynth. Res. 125: 151-166, 2015.

Butler W.L., Kitajima M.: Fluorescence quenching in photosystem II of chloroplasts. - Biochim. Biophys. Acta 376: $116-125,1975$.

Chen L.S., Cheng L.: Photosystem II is more tolerant to high temperature in apple (Malus domestica Borkh.) leaves than ifruit peel. - Photosynthetica 47: 112-120, 2009.

Christen D., Schönmann S., Jermini M. et al.: Characterization and early detection of grapevine (Vitis vinifera) stress responses to esca disease by in situ chlorophyll fluorescence and comparison with drought stress. - Environ Exp. Bot. 60: 504-514, 2007.

Essemine J., Govindachary S., Ammar S. et al.: Enhanced sensitivity of the photosynthetic apparatus to heat stress in digalactosyl-diacylglycerol deficient Arabidopsis. - Environ. Exp. Bot. 80: 16-26, 2012.

Gill M.: Heavy metal stress in plants: a review. - Int. J. Adv. Res. 2: 1043-1055, 2014.

Gill R.A., Zang L., Ali B. et al.: Chromium-induced physiochemical and ultrastructural changes in four cultivars of Brassica napus L. - Chemosphere 120: 154-164, 2015.

Gill S.S., Tuteja N.: Reactive oxygen species and antioxidant machinery in abiotic stress tolerance in crop plants. - Plant Physiol. Biochem. 48: 909-930, 2010

Govindjee: Sixty-three years since Kautsky: chlorophyll a fluorescence. - Funct. Plant Biol. 22: 131-160, 1995.

Hawkes J.S.: What is a „Heavy metal“? - J. Chem. Educ. 74: 1369-1374, 1997.
Hsu B.D., Lee Y.S., Jang Y.R. et al.: A method for analysis of fluorescence induction curve from DCMU-poisoned chloroplasts. - BBA-Bioenergetics 975: 44-49, 1989.

Joly D., Carpentier R. et al.: Sigmoidal reduction kinetics of the photosystem II acceptor side in intact photosynthetic materials during fluorescence induction. - Photochem. Photobiol. Sci. 8: 167-173, 2009.

Kalaji H.M., Jajoo A., Oukarroum A. et al.: The use of chlorophyll fluorescence kinetics analysis to study the performance of photosynthetic machinery in plants. - In: Parvaiz A., Rasool S. (ed.): Emerging Technologies and Management of Crop Stress Tolerance. Pp. 347-384. Elsevier Academic Press, San Diego 2014.

Kalaji H.M., Carpentier R., Allakhverdiev S.I. et al.: Fluorescence parameters as early indicators of light stress in barley. - J. Photoch. Photobio. B 112: 1-6, 2012.

Lazár D.: The polyphasic chlorophyll $a$ fluorescence rise measured under high intensity of exciting light. - Funct. Plant Biol. 33: 9-30, 2006.

Mathur S., Jajoo A.: Investigating deleterious effects of ultraviolet (UV) radiations on wheat by a quick method. - Acta Physiol. Plant. 37: 121-127, 2015.

Mathur S., Mehta P., Jajoo A.: Effects of dual stress (high salt and high temperature) on the photochemical efficiency of wheat leaves (Triticum aestivum). - Physiol. Mol. Biol. Plants 19: 179-188, 2013

Mathur S., Allakhverdiev S.I., Jajoo A.: Analysis of high temperature stress on the dynamics of antenna size and reducing side heterogeneity of Photosystem II in wheat leaves (Triticum aestivum). - Biochim. Biophys. Acta 1807: 22-29, 2011.

Neubauer C., Schreiber U.: The polyphasic rise of chlorophyll fluorescence upon onset of strong continuous illumination. I. Saturation characteristics and partial control by the photosystem acceptor side. - Z. Naturforsch. 42: 1246-1254, 1987.

Papageorgiou G.C., Govindjee: Photosystem II fluorescence: slow changes-scaling from the past. - J. Photoch. Photobio. B 104: 258-270, 2011

Scoccianti V., Crinelli R., Tirillini B. et al.: Uptake and toxicity of Cr (III) in celery seedlings. - Chemosphere 64: 1695-1703, 2006.

Shanker A.K., Cervantes C., Loza-Tavera H. et al.: Chromium 
toxicity in plants. - Environ. Int. 31: 739-753, 2005.

Sharma D.C., Sharma C.P., Tripathi R.D.: Phytotoxic lesions of chromium in maize. - Chemosphere 51: 63-68, 2003.

Srivastava A., Strasser R.J., Govindjee: Greening of peas: parallel measurements of $77 \mathrm{~K}$ emission spectra, O-J-I-P chlorophyll a fluorescence transient, period four oscillation of the initial fluorescence level, delayed light emission, and P700. - Photosynthetica 37: 365-392, 1999.

Strasser R.J., Tsimilli-Michael M., Srivastava A.: Analysis of chlorophyll $a$ fluorescence transient. - In: Papageorgiou G., Govindjee (ed.): Advances in Photosynthesis and Respiration: Chlorophyll $a$ Fluorescence: A Signature of Photosynthesis. Pp. 321-362. Springer, Dordrecht 2004.

Strasser R.J., Tsimilli-Michael M.: Activity and heterogeneity of PSII probed in vivo by the chlorophyll a fluorescence rise O(K)-J-I-P. - In: Garab G. (ed.): Photosynthesis: Mechanisms and Effects. Pp. 4321-4324. Kluwer Academic Publishers, Dordrecht 1998.

Subrahmanyam D.: Effects of chromium toxicity on leaf photosynthetic characteristics and oxidative changes in wheat (Triticum aestivum L.). - Photosynthetica 46: 339-345, 2008.

Tsimilli-Micheal M., Strasser R.J.: In vivo assessment of stress impact on plant's vitality: Applications in detecting and evaluating the beneficial role of mycorrhization on host plants. - In: Varma A. (ed.): Mycorrhiza. Pp. 679-703. SpringerVerlag, Berlin, Heidelberg, 2008.

Tomar R.S., Mathur S., Allakhverdiev S.I., Jajoo A.: Changes in PS II heterogeneity in response to osmotic and ionic stress in wheat leaves (Triticum aestivum). - J. Bioenerg. Biomembr. 44: 411-419, 2012.

Tomar R.S., Jajoo A.: Photomodified fluoranthene exerts more harmful effects as compared to intact fluoranthene by inhibiting growth and photosynthetic processes in wheat. Ecotoxicol. Environ. Safe. 122: 31-36, 2015.

Tomar R.S., Jajoo A.: A quick investigation of the detrimental effects of environmental pollutant polycyclic aromatic hydrocarbon fluoranthene on the photosynthetic efficiency of wheat (Triticum aestivum). - Ecotoxicology 22: 1313-1318, 2013.

Tóth S.Z., Schansker G., Strasser R.J.: In intact leaves, the maximum fluorescence level (FM) is independent of the redox state of the plastoquinone pool: a DCMU-inhibition study. BBA-Bioenergetics 1708: 275-282, 2005.

Vázques M.D., Poschenrieder Ch., Barceló J.: Chromium (VI) induced structural changes in bush bean plants. - Ann. Bot.London 59: 427-438, 1987.

\section{Appendix}

Derivation of the JIP-test parameters directly obtained from the recorded fluorescence transients [after Chen and Cheng (2009), Strasser et al. (2004)].

\begin{tabular}{ll}
\hline Fluorescence parameters & Description \\
\hline $\mathrm{F}_{0}$ & $\begin{array}{l}\text { Minimum reliable recorded fluorescence at } 50 \mu \text { s with the PEA } \\
\text { Maximum fluorescence } \\
\text { Variable fluorescence }\end{array}$ \\
$\mathrm{F}_{\mathrm{M}}$ & $\begin{array}{l}\text { Maximum quantum yield of primary photochemistry at } \mathrm{t}=0 \\
\mathrm{~F}_{\mathrm{V}}\end{array}$ \\
Yields or flux ratios & $\begin{array}{l}\text { Quantum yield for electron transport at } \mathrm{t}=0 \\
\text { Probability (at time } 0) \text { that a trapped exciton moves an electron into the } \\
\text { electron transport chain beyond } \mathrm{Q}_{\mathrm{A}}^{-}\end{array}$ \\
$\varphi_{\mathrm{E} 0}=\mathrm{TR} 0 / \mathrm{TBS}=1-\mathrm{F}_{0} / \mathrm{F}_{\mathrm{m}}=\mathrm{F}_{\mathrm{v}} / \mathrm{F}_{\mathrm{m}}=\left(\mathrm{F}_{\mathrm{v}} / \mathrm{F}_{\mathrm{m}}\right) \times\left(1-\mathrm{V}_{\mathrm{J}}\right)$ & $\begin{array}{l}\text { Efficiency with which an electron can move from the reduced } \\
\text { intersystem electron acceptors to the PSI end electron acceptors }\end{array}$ \\
$\psi_{0}=\mathrm{ET}_{0} / \mathrm{TR}_{0}=1-\mathrm{V}_{\mathrm{J}}$ & $\begin{array}{l}\text { Quantum yield of electron transport from } \mathrm{Q}_{\mathrm{A}}^{-} \text {to the PSI end electron } \\
\text { acceptors }\end{array}$ \\
$\delta_{\mathrm{R} 0}=\mathrm{RE}_{0} / \mathrm{ET} \mathrm{T}_{0}=\left(1-\mathrm{V}_{\mathrm{I}}\right) /\left(1-\mathrm{V}_{\mathrm{J}}\right)$ & Conformation term for primary photochemistry
\end{tabular}

Phenomenological fluxes or activities expressed per excited cross section (CS)

$\mathrm{ABS} / \mathrm{CS}_{\mathrm{m}}=\mathrm{F}_{\mathrm{m}}$

$\mathrm{TR}_{0} / \mathrm{CS}=\left(\mathrm{TR}_{0} / \mathrm{ABS}\right) /(\mathrm{ABS} / \mathrm{CS})$

$\mathrm{ET}_{0} / \mathrm{CS}=\left(\mathrm{ET}_{0} / \mathrm{RC}\right)(\mathrm{RC} / \mathrm{CS})$

$\mathrm{DI}_{0} / \mathrm{CS}=(\mathrm{ABS} / \mathrm{CS})-\left(\mathrm{TR}_{0} / \mathrm{CS}\right)$

Absorption flux per CS at $\mathrm{t}=\mathrm{tF}_{\mathrm{m}}$

Trapping at time zero, per CS

Electron transport at time zero, per CS

Dissipation at time zero, per CS

Vitality indexes

$\mathrm{PI}_{(\mathrm{ABS})}=[\mathrm{RC} / \mathrm{ABS}]\left[\Phi_{\mathrm{P} 0} /\left(1-\Phi_{\mathrm{P} 0}\right)\right]\left[\psi_{0} /\left(1-\psi_{0}\right)\right]$

$\mathrm{SFI}_{(\mathrm{ABS})}=\left(\mathrm{Chl}_{\mathrm{RC}} / \mathrm{Chl}_{\mathrm{tot}}\right) * \varphi \mathrm{P} 0 * \Psi_{0}$

$\mathrm{DF}=\log \mathrm{PI}_{(\mathrm{X})}$

Performance Index on the basis of absorbance

Structure function index for photosynthetic system

Driving force for photosynthesis 